\title{
Inmunobiología de la reproducción: II. Inmunología de la relación materno-fetal
}

\author{
Angela P. Cadavid, Jorge E. Ossa*
}

\begin{abstract}
RESUMEN: El presente artículo es una revisión de la literatura sobre los fenómenos inmunológicos comprometidos en el reconocimiento alogénico de la madre hacia el feto. Se hace una descripción de los antígenos que pueden estar involucrados y de los diferentes mediadores inmunológicos como los anticuerpos, las linfoquinas, los factores de crecimiento y algunos factores supresores producidos por células deciduales y trofoblásticas. A manera de ejemplo se mencionan algunas de las patologías que se pueden presentar por alteración en la interfase materno-fetal como es el caso del aborto recurrente espontáneo.
\end{abstract}

PALABRAS CLAVES: Interfase materno fetal, embarazo, decidua, trofoblasto, aborto espontáneo recurrente.

SUMMARY: The present article is a review of the literature on immunologic phenomena taking place in the allogenic recognition of the fetus by the pregnant mother. Antigens, antibodies, lymphokines, growth factors and suppressor factors possibly involved are discussed. Pathologies like recurrent spontaneous abortion are mentioned as example of alteration of the materno-fetal interface.

KEY WORDS: Materno-fetal interface; pregnancy; decidua; trophoblast; recurrent spontaneous abortion.

El feto hereda el patrimonio genético de cada uno de los padres, incluyendo la información para el complejo mayor de histocompatibilidad $(\mathrm{CMH})$. Lo anterior implica que hasta un 50\% de su constitución genética puede ser diferente a la madre y por lo tanto tiene todas las características de un trasplante alogénico.

Desde la concepción y a través de su desarrollo, el feto puede considerarse un aloinjerto: El espermatozoide que fecunda el óvulo pertenece a un individuo genéticamente diferente a la madre y expresa moléculas antigénicas (1); de igual manera, el huevo y posteriormente el blastocito (2), el embrión y el feto expresan antígenos de histocompatibilidad tanto paternos como maternos $(3,4)$, pero, contrario a lo que ocurre con los trasplantes de órganos, el feto no sufre rechazo. La naturaleza ha creado mecanismos que desde el momento mismo de la copulación garantizan la perpetuación de las especies: Así por ejemplo, en el semen $\mathrm{y}$ en las secreciones genitales femeninas existen factores inmunosupresores que bloquean el reconocimiento antigénico de los espermatozoides $(1,5)$; el blastocito pre-implantación pierde la expresión de antígenos de histocompatibilidad (6) y produce algunos factores supresores (7). Por otra parte, las células deciduales materrias en el período peri-implantación crean una situación de inmunosupresión local que favorece el proceso de implantación $(8,9)$.

El éxito de la gestación, aparentemente en contra de las leyes de histocompatibilidad, se ha pretendido explicar por diferentes teorías, algunas de las cuales se han revaluado y para otras se presentan nuevas alternativas que toman más

* Grupo Inmunobiología de la Reproducción. Facultad de Medicina, Universidad de Antioquia. fuerza a medida que avanzan los estudios de la interfase materno-fetal.

Ya hemos mencionado que el feto expresa antígenos de histocompatibilidad tanto mayores como menores. Estudios en varias especies de roedores revelan que el producto de la concepción expresa en su capa externa antígenos $\mathrm{H}-\mathrm{Y}$ (asociados al sexo masculino), Ags menores de trasplante, Ags específicos de órgano y Ags embrionarios (oncofetales), por lo tanto la teoría del feto inmunológicamente neutro no tiene fundamento. Además la madre no adquiere tolerancia a los antígenos fetales, porque, entre otras evidencias, ella rechaza cualquier injerto proveniente del feto que le sea colocado posteriormente $(3,4)$. Tampoco puede considerarse el útero como un sitio inmunológicamente privilegiado por muchas razones directas e indirectas: 1) Los injertos que se implanten en el útero normalmente son rechazados; 2) el útero tiene drenaje linfático para-aórtico y en estos ganglios se observa hipertrofia durante la gestación (3), 3) Los embarazos extrauterinos no fracasan precisamente por rechazo inmunológico y 4) podría especularse que si el útero fuera inmunológicamente privilegiado, estaría aislado del sistema inmune y en consecuencia podrían producirse embarazos entre especies diferentes al transferir embriones (4).

$\mathrm{La}$ inmunosupresión materna es un fenómeno que merece más discusión, porque si bien es cierto que la gestante tiene algún grado de inmunodepresión, explicable por los niveles de estrógenos y progesterona, ella conserva la capacidad de responder a infecciones y de rechazar injertos, aún de origen paterno, en sitios extra-uterinos (4).

El papel central en la inmunología de la gestación se ha atribuido a la placenta la cual está constituida por dos unidades básicas: la decidua o componente materno y el trofoblasto que se origina de tejidos embrionarios. 
La decidua se desarrolla en el endometrio por una reacción especial (decidualización) muy similar a una respuesta inflamatoria y consistente en la proliferación del epitelio uterino, las glándulas y el tejido conectivo estromal. Esta reacción se lleva a efecto por acción de la progesterona y, de un estímulo que puede estar dado por el blastocito o en condiciones experimentales, por agentes artificiales tales como aceite, aire, irritantes químicos o trauma uterino (10). Las funciones biológicas de la decidua incluyen: la nutrición del embrion, la secreción de hormonas, proteínas y otras moléculas que controlan la invasión de la pared uterina por parte del trofoblasto y el sostenimiento de la placenta en el útero por secreción de colágeno y matriz extracelular. Además, la decidua sirve como una zona de "amortiguación inmunológica" para proteger la unidad fotoplacentaria del rechazo materno (11), aunque los mecanismos de dicho efecto "amortiguador" todavía no están esclarecidos.

Varios tipos de células conforman la decidua: 1) Las células deciduales tipo estromales que son células largas con núcleos poliploides e inclusiones citoplasmáticas, totalmente dependientes de la progesterona para su formación y mantenimiento y posiblemente se derivan de células mesenquimales indiferenciadas; 2) las células de las glándulas endometriales que son grandes y granuladas y se intercalan con las células deciduales durante la decidualización temprana, provienen de precursores de linfocitos en la médula ósea y tienen RFc para la IgG; 3 ) además en la decidua se encuentran linfocitos $(80 \%$ son células nulas o sea sin marcadores clásicos), monocitos/macrófagos, células NK (la mayoría inactiva) y células presentadoras de antígeno, lo cual está indicando que la decidua tiene toda la capacidad de iniciar y efectuar una respuesta inmune contra el reto antigénico que presenta el feto $(12,13)$. Pero, por otro lado, se ha encontrado que los linfocitos $\mathrm{T}$ de la decidua humana de primer trimestre, carecen de receptores para el antígeno (TCR) tanto en la forma $\alpha / \beta$ como en la $\tau / \delta$, pero poseen el marcador CD3. Esta ausencia de TCR puede ser muy importante en el fenómeno de aceptación inmunológica del aloinjerto fetal al no ser activadas estas células por los antígenos (incluyendo los antígenos paternos del feto). Esta deficiencia de TCR parece que no es intrínseca sino modulada por factores uterinos locales (14).

El trofoblasto, componente fetal de la placenta, se origina del trofoectodermo y está constituido por varias poblaciones que tienen características morfológicas y anatómicas diferentes. Las vellosidades placentarias contienen dos capas: el sincitiotrofoblasto y el citotrofoblasto velloso. Parte del citotrofoblasto migra de las vellosidades y se convierte en el citotrofoblasto no-velloso el cual invade el lecho placentario, el intersticio y las arterias espirales maternas y también forma parte de las membranas cariónicas que rodean el feto (15).

Los diferentes tipos de trofoblasto expresan antígenos que pueden jugar un papel importante en la interfase materno-fetal porque hacia los mismos puede dirigirse el reconocimiento materno. Estos antígenos son:

1- Antígenos del Complejo Mayor de Histocompatibilidad $(\mathrm{CMH})$ : En el sincitiotrofoblasto y en el citotrofoblasto velloso no se ha podido detectar expresión de antígenos del CMH I ni II; sin embargo en el citotrofoblasto no-velloso (que está en más íntimo contacto con los tejidos maternos), se ha encontrado expresión de un antígeno clase-I no clásico que tiene la cadena liviana de $\boldsymbol{\beta}^{2}$-microglobulina (identificada por el AbMo W6/32) y una cadena pesada con un peso molecular menor que el de los antígenos CMH-I clásicos ( $39 \mathrm{Kd}$ vs $44 \mathrm{Kd}$ ). Este antígeno no presenta el polimorfismo de los antígenos clásicos y no se reconoce con antisueros contra determinantes alotípicos de los CMH-I. Se han sugerido dos posibilidades para explicar estos antígenos: Que sean versiones incompletas de los CMH-I cuyos genes son transcritos tempranamente por el citotrofoblasto no-velloso, o que estos antígenos no sean antígenos HLA, sino que estén codificados por genes teloméricos al $\operatorname{HLA}-A(13,16)$. Recientemente, por técnicas de biología molecular, se clonaron y secuenciaron tres genes HLA no-clásicos (E, F y G). El gene asociado con el trofoblasto parece ser el HLA-G (17-19).

2- Antígenos de reacción cruzada trofoblasto-linfocito (TLX): Son antígenos que se encuentran en el trofoblasto, linfocitos, plaquetas y plasma seminal. Se considera que estos antígenos están involucrados en la red auto-anti-idiotípica de la respuesta inmune en la gestación y que es hacia ellos que está dirigida la respuesta de reconocimiento materna. Su presencia en el plasma seminal puede ser necesaria para iniciar la sensibilización materna y la producción de anticuerpos adecuados que posteriormente recubran los antígenos en el trofoblasto. A los TLX se les ha atribuido un papel protagónico en la patogénesis del aborto habitual (16).

Si revisamos una de las primeras publicaciones de Faulk sobre el TLX (20), se refiere a un antígeno TA que se expresa sólo en trofoblasto y un antígeno $\mathrm{TA}_{2}$ que se expresa en linfocitos y trofoblasto; los anticuerpos que se forman contra el $\mathrm{TA}_{2}$, protegerían a los antígenos $\mathrm{TA}_{1}$ de la respuesta inmune efectora materna. Podría pensarse a la luz de la información más reciente que el HLA-G es el equivalente al TA $A_{1}$ que se encuentra en trofoblasto y que el TLX es el equivalente al $\mathrm{TA}_{2}$, que es el responsable de inducir la respuesta protectora materna. Los anticuerpos que se producen contra el TLX presente en plasma seminal, linfocitos y plaquetas estarían bloqueando la reacción contra los antígenos HLA-G que se expresan en trofoblasto.

3- Receptor Fc ( $\mathrm{RFc}$ ) para el transporte de la IgG de la madre al feto: Se ha postulado como candidato de inducción alogénica de la respuesta inmune provocando la formación de anticuerpos bloqueadores (AcB) contra este RFc. Estudios de familias han sugerido que el gen para el RFc puede estar ligado al HLA. Recientemente se ha descrito una molécula de RFc soluble en plasma seminal, la cual puede representar un mecanismo adicional para la inducción de $\mathrm{AcB}$ y puede estar relacionado con la regulación inmunológica durante la fertilización y la implantación (16).

4- Fosfatasa alcalina placentaria: Su expresión en el sincitiotrofoblasto aumenta con el progreso de la gestación; la enzima es altamente polimórfica pero no se ha descrito inmunoreactividad materna al isotipo paterno (16).

5- Receptores de transferrina: Se encuentran en muchos tipos de células que están proliferando aceleradamente. No se han informado Acs maternos contra estos receptores, pero se supone que deban existir y que tal respuesta esté asociada con alteración de los eventos metabólicos de la placenta, 
dada la asociación de estos receptores con la vía de producción de energía de la transferrina NADH-reductasa diférrica (16)

6- Proteína básica mayor: Se ha identificado en citotrofoblasto no-velloso; puede tener la función de controlar la invasión del trofoblasto a los tejidos maternos ya que tiene propiedades citotóxicas y parasiticida por inducción de la liberación de histamina por basófilos y mastocitos. Los niveles de proteína básica mayor en el plasma aumentan desde el comienzo de la gestación, alcanzan un pico máximo hacia la semana 20 ocurriendo un segundo pico hacia el final de la gestación y durante el parto. Se desconoce el papel de este factor en el aborto espontáneo pero se ha informado que las abortadoras no alcanzan una concentración adecuada en su sangre periférica (16). Esta proteína se encuentra en las células $\mathrm{X}$ del trofoblasto que son células gigantes que se depositan en la placa basal de la placenta humana. Anormalidades en estas células se observan en placentas de abortadoras recurrentes, en placentas de gestaciones con retardo de crecimiento intrauterino y en casos de hipertensión inducida por el embarazo (11).

7- Receptores para factores de crecimiento e insulina y antígenos del factor $\mathrm{V}$ de la coagulación: se han identificado en el sincitiotrofoblasto por anticuerpos monoclonales. No se han encontrado anticuerpos maternos contra ellos (16).

Para poder avanzar en el entendimiento de la respuesta inmune durante la gestación hay que partir de la base, sorprendente por lo demás, que la madre debe reconocer como extraño a su feto para poder protegerlo del ataque inmune efector. Prueba de la necesidad de este reconocimiento es la de que cuando hay una mayor disparidad genética entre los miembros de una pareja y ya ha ocurrido una inmunización previa de la madre (el caso de multíparas), se produce una mayor invasión del trofoblasto, una mayor respuesta decidual y un mayor peso de la placenta (3).

Diferentes mecanismos se mencionan para aclarar estos fenómenos, pero ninguno es capaz por sí solo de explicar la respuesta inmune que se presenta entre la madre y el feto. Es posiblemente la interacción entre dichos mecanismos lo que nos podría dar alguna luz en esta intrincada relación:

1- Anticuerpos bloqueadores (AcB). Son anticuerpos del isotipo $\mathrm{IgG}$, pueden ser detectados en primigrávidas desde la semana 12 de gestación y en eluídos de placentas a término. No están dirigidos contra antígenos HLA-I clási$\cos (\mathrm{A}, \mathrm{B}, \mathrm{C})$. Se ha establecido asociación entre el crecimiento del trofoblasto y la aparición de AcB que inhiben la respuesta inmune celular materna a antígenos paternos, posiblemente por enmascaramiento de antígenos HLA-II en las células estimuladoras alogénicas y por esto inhiben el CML. Los antígenos que inducen la producción de estos AcB no se conocen pero podrían ser los TLX. Los AcB están ausentes en mujeres con aborto recurrente y si el mecanismo de este aborto es un reconocimiento alogénico insuficiente, es necesario provocar un estímulo aloantigénico adicional con linfocitos paternos o de donantes (21).

2- Anticuerpos contra el RFc. Son anticuerpos no-citotóxicos, se pueden detectar desde la cuarta semana de gestación y están ausentes en la mayoría de las pacientes con aborto recurrente. Estos AcB contra el RFc pueden ser inducidos por transfusiones sanguíneas en receptores de trasplan- tes aunque no se conoce muy bien su papel (21).

3- Células con actividad supresora. Tres tipos de células con actividad inmunosupresora se han identificado en la decidua:

a- Células estromales dependientes de hormona que liberan $\mathrm{PGE}_{2}$ la cual bloquea la producción de IL-2 y regula la expresión de receptores para IL-2 (RIL-2) en las células $\mathrm{T}$ ayudadoras.

b- Células grandes no granuladas aisladas de la decidua en la etapa inicial, son dependientes de hormonas, bloquean la vía aferente de la respuesta inmune a antígenos embrionarios e inhiben la generación de células T citotóxicas contra antígenos no-MHC. Su actividad decae a medida que el embarazo progresa y son reemplazadas por células de pequeño tamaño.

c- Linfocitos pequeños con gránulos, tienen $\mathrm{RFc}$ para IgG, se activan por señales provenientes de trofoblasto. Liberan factores que bloquean la respuesta de linfocitos $\mathrm{T}$ y células NK maternas a la IL-2; este factor puede bloquear la acción de la IL-3 que activa las células citotóxicas naturales y además inhibir el IFN- $\tau$ y la activación de macrófagos por LPS.

En las mujeres con aborto espontáneo recurrente no se ha encontrado actividad de las células supresoras en la decidua $(12,21)$.

4.Citoquinas y factores de crecimiento. La respuesta inmune materna a antígenos fetales está además mediada por interacciones celulares y la liberación de factores solubles como las linfoquinas. Brevemente revisaremos la secuencia de producción de estas linfoquinas:

Cuando un antígeno entra en contacto con el sistema inmune, las células presentadoras del antígeno lo procesan y lo presentan a los linfocitos T (LT), liberando además interleuquina-1 (IL-1). Esta última induce a los LT ayudadores a que secreten IL-2 que es el principal factor de crecimiento y diferenciación de los LT e induce la actividad de células T citotóxicas (CTL), células asesinas naturales (NK) y células asesinas activadas por linfoquinas (LAK). Además, la IL-2 induce proliferación y diferenciación de LB y en una forma autocrina regula la expresión del receptor para IL-2 (RIL-2) en los propios LT. Otras linfoquinas secretadas por los LT son: el IFN- $\tau$ que estimula la secreción de Igs por los LB, activa células NK e inducen la expresión de Ags del CMH. La Il-4 es un factor de crecimiento para LB, mastocitos y células progenitoras hematopoyéticas. Igualmente aumenta la proliferación de LB y la secreción de IgGı e IgE. La IL-5 incrementa la proliferación de LB y la secreción de $\operatorname{IgA}$, IgM, e IgG. Además se secretan los factores estimuladores de colonias CSFs y la IL-3 que juegan un papel importante en la proliferación y actividad funcional de subpoblaciones de células precursoras hematopoyéticas $(21,22)$.

Cada una de estas linfoquinas cumple un papel particular en la gestación:

a- IL-1. Ayuda a promover el desarrollo fetal y al parecer puede inducir la proliferación de células en la barrera placentaria. Además aumenta la producción de las hormonas adrenocorticotrópica, luteinizante y prolactina e igualmente la secreción de progesterona y estrógenos por la placenta (22).

b- IL-2. La poca producción y actividad de esta linfoquina 
en la interfase materno-fetal parece ser un elemento fundamental en el éxito del embarazo. El bloqueo de la producción, función y expresión del RIL-2, incrementaba la modulación y eliminación de reacciones citotóxicas contra el feto en desarrollo. Hay aspectos importantes para recalcar: 1) Los linfocitos a nivel placentario tienen capacidad disminuida de producir IL-2; 2) hay factores reguladores de la placenta que restringen la expresión de RIL-2; 3) los linfocitos endometriales en gestaciones tempranas normales no expresan este receptor, sin embargo en decidua de abortadoras habituales de 8-10 semanas se encuentran linfocitos con RIL-2 (22).

c- IL-4 e IL-5. Su papel en la gestación no ha sido aclarado pero se podría suponer que intervienen en la producción de la $\mathrm{IgG}_{ı}$ no fijadora de complemento, específica para antígenos fetales. Así mismo la IL-4 suprime la activación de células LAK y pudiera estar comprometida en incrementar la capacidad fagocítica del trofoblasto (22).

d- CSFs e IL-3. Producidas por células de la decidua y del trofoblasto. Son responsables de la estimulación de macrófagos, de la síntesis de moléculas biológicamente activas y de la expresión de varios marcadores de membrana. Además aumentan la capacidad proliferativa y fagocítica del trofoblasto $(13,22)$. El GM-CSF (factor estimulador de colonias de granulocitos y macrófagos), se ha encontrado presente en placenta humana. Tiene la capacidad de prevenir la reabsorción fetal espontánea e incrementar el tamaño del feto y de la placenta cuando se inyecta intraperitonealmente en ratones preñados. Puede promover la liberación de citoquinas por células $\mathrm{CD} 8+(24)$.

El CSF-1 (factor estimulador de colonias-1) ha sido involucrado en la reproducción como un factor de crecimiento placentario y sus niveles están aumentados hasta 1000 veces en el útero durante la gestación. Las principales productoras de CSF-1 son las células de las glándulas epiteliales uterinas, aunque las células de las glándulas endometriales también pueden producirlo. El receptor para el CSF-1 es producto del proto-oncogen $c$-fms que está expresado en células de trofoblasto murino. En placenta humana no está definido el gen que codifica para este receptor, porque hay múltiples sitios de iniciación de la transcripción (24).

e- IFN: Un IFN- $\alpha$ producido por blastocitos bovinos y porcinos en el período peri-implantación parece que tienen una importante función en el mantenimiento de la función del cuerpo lúteo en la gestación temprana y tienen además actividad antiviral y antiproliferativa para proteínas purificadas (25).

f- Factores de crecimiento y diferenciación. El factor transformante de crecimiento $\beta_{2}$ (TGF- $\beta_{2}$ ) puede inhibir el crecimiento del trofoblasto y regular negativamente los cambios celulares inducidos por citoquinas inflamatorias como la IL-1 y el factor del necrosis tumoral alfa (FNT- $\alpha)$. El GM-CSF y la IL-3 pudieran estar estimulando a las células deciduales para producir TGF- $\beta_{2}$ (26). En la decidua murina se ha aislado un potente factor inmunosupresor que está relacionado con el TGF- $\beta_{2}$ el cual tiene efecto supresor de la generación de CTLs, NK, LAK, de la producción de anión superóxido y de factor de necrosis tumoral (FNT- $\alpha$ ) por parte de los macrófagos (27).

La producción de otros factores como la gonadotropina coriónica humana y la hormona luteinizante y la presencia de receptores para los mismos, permiten suponer que estos factores tienen un papel en el mantenimiento de la gestación (23). Posiblemente exista un control feto-placentario de algunos factores de crecimiento como la prolactina, el factor de crecimiento insulinoide, el factor de crecimiento epitelial y otros, que tienen efectos en la proliferación y diferenciación de la placenta. Todavía se requieren más estudios para esclarecer los efectos y las interacciones de estos factores (23).

5- Red idiotipo-anti-idiotipo. Esta red ofrece una explicación para la regulación de la inmunidad humoral y celular en la gestación.

En condiciones normales, a medida que van ocurriendo las gestaciones, hasta un $50 \%$ de las mujeres desarrollan anticuerpos citotóxicos contra los HLA del cónyuge, pero no hay evidencias que éstos afecten el embarazo (de hecho tales anticuerpos se utilizan para la tipificación de tejidos). En el embarazo, se induce la producción de anti-anti-HLA o $\mathrm{Ac}_{2}$, éstos se pueden unir a las clonas de células $\mathrm{B}$ que producen $\mathrm{Ac}_{1}$ y regular la producción de los mismos. Además se producen autoanticuerpos específicos para el receptor idiotípico de las células maternas que están alosensibilizadas contra los linfocitos paternos, modulando también su acción. En la inmunidad anti-HLA paterna, hay un imbalance hacia la prevalencia de $A_{1}$, lo cual usualmente no representa problema (21).

Pero en el balance de la red idiotipo-anti-idiotipo contra los antígenos TLX paternos, si se pueden presentar proble-

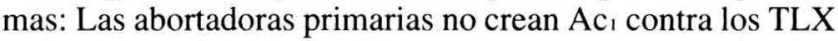
paternos porque no los reconocen como extraños; en cambio las abortadoras secundarias sí tienen $A c_{1}$ anti-TLX pero carecen de respuesta de $\mathrm{Ac}_{2}$ anti-anti-TLX y estos $A c_{1}$ serían perjudiciales para el éxito de la gestación (21).

En resumen, los aloantígenos TLX en el plasma seminal o en el trofoblasto pueden inducir un circuito que regula la inmunidad materna tanto humoral como celular (20).

6- Formación de la placa basal. La placa basal es una estructura constituida por una malla de fibrina que se encuentra en la unión de los tejidos trofoblásticos y maternos y contribuye de una manera importante en la estabilidad de la placenta en el útero y además se asocia con la adhesión de las vellosidades en la decidua. El reconocimiento alogénico de los tejidos embrionarios estimula la inmunidad mediante la activación de los LT ayudadores los cuales secretan el factor activador de macrófagos, que hace que éstos produzcan IL-1. Esta sustancia regula la liberación de un factor tisular, el cual a su vez activa la vía extrínseca de la coagulación y posteriormente lleva al depósito de fibrina. Esta última luego se polimeriza en una matriz más estable por el factor XIII. El inadecuado reconocimiento materno puede dar origen a falla en la implantación o a defecto en la formación de la placa basal. Este podría ser uno de los mecanismos por los cuales los anticuerpos anti-fosfolípidos ocasionan el aborto habitual, teniendo en cuenta que los mismos interfieren con la vía extrínseca de la coagulación y bloquean la formación de la capa de fibrina, llevando por lo tanto a la falla (21).

De todo lo anteriormente expuesto se puede concluir la importancia que tiene el reconocimiento alogénico para el desarrollo de la gestación. El mecanismo preciso por el cual 
se logra mantener el "injerto fetal" no está definido y posiblemente sea la combinación de varios procesos. Algunas fallas en este reconocimiento han llevado a patologías como el aborto habitual. Así mismo, la hipertensión inducida por el embarazo y el retardo en el crecimiento intrauterino posiblemente sean manifestaciones más tardías del mismo fenómeno de falta de reconocimiento alogénico.

El conocimiento de esta interacción en la interfase materno-fetal ha permitido hacer algunas intervenciones terapéuticas exitosas en entidades como el aborto recurrente espontáneo de origen inmunológico. Hasta ahora se ha encontrado que el compromiso inmunológico puede ser: aloinmune por el no reconocimiento materno de los antígenos paternos presentes en el feto y para esto se han realizado transfusiones con linfocitos paternos y/o de donantes con diversos protocolos y con éxitos entre un $50-90 \%$ en los diferentes grupos; el objetivo de estas transfusiones es sobreestimular el sistema inmune para que reconozca los antígenos paternos (posiblemente el TLX) y desencadene la respuesta adecuada en el embarazo. Los que están en contra de esta terapia argumentan el porcentaje de $20-35 \%$ de embarazos en estas pacientes sin tratamiento. El otro compromiso inmunológico en el aborto recurrente espontáneo es el de autoinmunidad en la cual la madre desarrolla autoanti- cuerpos contra epítopes de fosfolípidos cargados negativamente y desencadena una reacción de trombosis e insuficiencia placentaria al parecer por un disbalance en la producción de prostaciclina y tromboxano. El tratamiento de este fenómeno con anticoagulantes y antiinflamatorios ha permitido embarazos exitosos hasta en un $80 \%$. La coexistencia de ambos fenómenos (alo y autoinmune) puede darse, y al parecer con cada aborto de cualquier causa, se aumenta en un $10-15 \%$ el riesgo de sensibilizarse contra fosfolípidos (28). Estos problemas y los posibles mecanismos inmunopatogénicos implicados, serán el objeto de otra contribución.

No conocemos en nuestro medio la frecuencia de los abortos recurrentes espontáneos de origen inmunológico aloinmune ni autoinmune y en este sentido se están desarrollando algunos protocolos de investigación por parte del Grupo Inmunobiología de la Reproducción de la Universidad de Antioquia, con el fin de establecer un centro de diagnóstico de estas alteraciones y proponer terapias adecuadas.

\section{Agradecimientos}

A los integrantes del Grupo Inmunobiología de la reproducción por sus aportes y en especial al Dr. José Luis Ramírez por la revisión del manuscrito.

\section{BIBLIOGRAFIA}

1. Alexander NJ., Anderson DJ. Immunology of semen. Fertil Steril 1987; 47(2): 192-205.

2. Nilsson BO., Bergstrom S., Hakansson I. et al. Ultrastructure of Implantation. Upsala J Med Sci 1978; suppl 22: 27-38.

3. Beer AE., Billingham RE. The embryo as a transplant. Sci Am 1974; 230: 36-46.

4. Chaouat G. La defensa del feto contra su madre. Mundo Cient 1986; 6: 718-730.

5. James K., Hargreave T. Immunosuppression by seminal plasma and its possible clinical significance. Immunol Today 1984; 5(12):357-363. Desoye G., Dohr GA., Motter W. et al. Lack of HLA Class I and Class II antigens on human preimplantation embryos. J Immunol 1988; 140(12): 4157-4159

7. Daya S., Clark D. Identification of two species of suppressive factor of differing molecular weight released by in vitro fertilized human oocytes. Fertil Steril 1988; 49(2): 360-363.

8. Kapovic M., Rukaviana D. Kinetics of lymphoproliferative responses of lymphocytes harvested from the draining lymph nodes during pregnancy in rats. J Rep Immunol 1990; (in press).

9. Matsui S., Yoshimura N., Oka T. Immunochemical characterization of the supressor factor from early human decidual cells. Transplantation 1989; 48(4): 651-654.

10. Finn CA. Implantation, menstruation and inflammation. Biol. Rev. 1986; 61: 313-328.

11. Beer AE. Immunologic aspects of normal pregnancy and recurrent spontaneous abortion. Semin Reprod Endocrinol 1988; 6(2): 163-178.

12. Daya S., Clark DA. Immunoregulation at the maternofetal interface Immunol Aller Clin N Am 1990; 10(1): 49-64.

13. Mogil RJ., Wegmann TG. Maternal immune reactivity as a determinant of placental function and fetal survival. Semin Reprod Endocrin 1988; 6(2): 145-154.

14. Dietl J., Horny HP., Ruck P. et al. Intradecidual T Lymphocytes Lack Immunohistochemically Detectable T-Cell Receptors. Am J Reprod Immunol 1990; 24: 33-36

15. Faulk WP., McIntyre JA. Immunological studies of human trophoblast: Markers, subsets and functions. Immunol Rev 1983; 75: 139-175.
16. Faulk WP., Path FRC., Hunt JS. Human trophoblast antigens. Immunol Aller Clin N Am 1990; 10(1): 27-48.

17. Kovats S., Main EK., Librach C. et al. A Class I Antigen, HLA-G, Expressed in Human Trophoblasts. Science 1990; 248: 220-223.

18. Hunt JS., HSI BL. Evasive Strategies of Trophoblast Cells: Selective Expression of Membrane Antigens. Am J Reprod Immunol 1990; 23: 57-63.

19. Ellis S., HLA G. At the Interface. Am J Reprod Immunol 1990; 23 : 84-86.

20. Faulk WP., Temple A., Lovins RE. et al. Antigens of human trophoblasts: A working hypothesis for their role in normal and abnormal pregnacies. Proc Natl Acad Sci 1978; 75(4): 1947-1951.

21. Thaler CJ., McIntyre JA. Fetal wastage and nonrecognition on human pregnancy. Immunol Aller Clin N Am 1990; 10(1): 79-98.

22. Toder V., Shomer B. The role of lymphokines in pregnancy. Immunol Aller Clin N Am 1990; 10(1): 65-77.

23. Morrish DW., Rao CH. Workshop on growth factors and placental differentiation. Placental communications 1990; 199: 101-104

24. Wegmann TG. The cytokine basis for cross-talk between the maternal immune and reproductive systems. Curr Opinion Immunol 1990; 2: 765-769.

25. Cross JC., Farin CE., Sharif SF. et al. Characterization of the Antiviral Activity Constitutively Produced by Murine Conceptuses: Absence of Placental mRNAs for Interferon Alpha and Beta. Molec Reprod Devel 1990; 26: 122-128.

26. Clark D. Paraimmunology in the Decidua? Am J Reprod Immunol 1990; 24: 37-39.

27. Clark D., Flanders KC., Banwatt D. et al. Murine pregnancy decidua produces a unique immunosuppressive molecule related to Transforming Growth Factor $\beta_{2}$. J Immunol 1990; 144(8): 3008-3014.

28. Beer AE., Kwak JY. What is the evidence for immunologic pregnancy loss?: Lymphocyte immunization the supportive view. American Fertility Society, 46th Annual meeting. 